\title{
Formation mechanism of bimetal composite layer between LCS and HCCI
}

\author{
Yong-chang Zhu ${ }^{1,2}$, *Zun-jie Wei ${ }^{1}$, Shou-fan Rong ${ }^{2}$, Hong-wei Wang ${ }^{1}$ and Chun-ming Zou ${ }^{1}$ \\ 1. School of Materials Science and Engineering, Harbin Institute of Technology, Harbin 154001, China \\ 2. Institute of Materials Science and Engineering, Jiamusi University, Jiamusi 154007, China
}

\begin{abstract}
A low carbon steel (LCS)/high chromium white cast iron ( $\mathrm{HCCl}$ ) bimetal wear plate about $20 \mathrm{~mm}$ in thickness was prepared by liquid-liquid bimetal composite casting technology to substitute for the welding wear plate. A clear and distinguishable composite layer between the LCS and the $\mathrm{HCCl}$ was detected with SEM, and the composition and phase were analyzed through EDS and XRD. The composite layer was composed of three sublayers from the LCS to the $\mathrm{HCCl}$ : pearlite transition layer, composite layer, and $\mathrm{HCCl}$ transition layer. The Vickers hardness from the pearlite transition layer to the $\mathrm{HCCl}$ transition layer was $360 \mathrm{HV}$ to $855 \mathrm{HV}$. The austenite grows as dendrites between the composite layer and the $\mathrm{HCCl}$ transition layer under constitutional undercooling. A large amount of $\mathrm{C}$ and $\mathrm{Cr}$, and a small amount of $\mathrm{Si}$ and $\mathrm{Mn}$ dissolve in the matrix. Granular $\mathrm{Cr}_{7} \mathrm{C}_{3}$ is uniformly distributed. Due to the solute redistribution at the solid-liquid interface, the primary austenite grows from planar to cellular and finally to the distinct dendrite crystals. The dendrite crystals have an obvious growth direction perpendicular to the composite layer.
\end{abstract}

Key words: liquid-liquid composite casting; bimetal wear plate; composite layer; dendritic austenite
CLC numbers: TG142.1
Document code: $\mathrm{A}$
Article ID: 1672-6421 (2016 06-396-06

$\mathrm{C}$ omposite wear resistant steel plates are widely used in the fields of metallurgy, cement, electricity, and mining under conditions of corrosive wear, impact abrasion and frictional wear. Currently, an automatic surfacing technique is the main way of producing a composite wear resistant steel plate that consists of the wear layer and the substrate. The self-shield hard alloy wire that serves as the wear layer is soldered to a soft substrate such as low-carbon steel, low-alloy steel or stainless steel. The wear layer is used to resist the impact abrasion or the grinding abrasion, and the substrate provides enough impact resistance toughness for the hard wear layer ${ }^{[1]}$. The automatic surfacing welds the composite layer during the non-uniform heating process, resulting in the residual stresses that cause a lot of deep transverse cracks. Meanwhile, the alloying elements of the wear layer are diluted by the substrate, which results in the variation of the wear layer performance from top to bottom. Therefore, it is difficult to obtain the optimal overall mechanical properties ${ }^{[2,3]}$.

\section{*Zun-jie Wei}

Male, Ph. D., Professor. Research direction: Solidification theory and new materials under ultra high pressure.

E-mail: weizj@hit.edu.cn

Received: 2015-12-07; Accepted: 2016-08-16
Liquid-liquid bimetal composite casting technology can achieve a large metallurgical composite interface between different metals, which provides a new method for solving the problems of transverse cracks and the uneven performance of the wear layer ${ }^{[4-6]}$. To date, liquid-liquid bimetal plate products mainly focus on the application of the liner, jaw and back plate, but using a liquid-liquid bimetal casting wear plate to replace the welding wear plate is still difficult due to its thinner thickness than that of the above mentioned bimetal products ${ }^{[7-10]}$. Therefore, the study of casting liquid-liquid large flat bimetal composite plate is important ${ }^{[11,12]}$.

In this study, liquid-liquid composite casting technology was used to produce the low-carbon steel (LCS) and high chromium white cast iron (HCCI) bimetal wear plates. A good metallurgically bonded interface between the wear layer and the substrate will be a critical determinant of a satisfactory bimetal wear plate ${ }^{[13,14]}$. In order to ensure the excellent metallurgical quality of the wear layer and effectively reduce the substrate alloy composition dilution effect on the wear layer, a kind of chilling material was laid in the bottom of the mould cavity to cause a higher temperature gradient and benefit the lamellar solidification of LCS. The microstructure of the composite layer was observed and the formation mechanism of the bimetal composite layer between LCS and HCCI was analyzed. 


\section{Experimental procedure}

In order to control the different pouring temperatures, two KGPS-800 medium frequency furnaces with $20 \mathrm{~kg}$ and 50 $\mathrm{kg}$ melting capacity were used for melting LCS and HCCI, respectively, whose nominal compositions are listed in Table 1. The $\mathrm{CO}_{2}$ blowing sand hardening method was used in this study, and the mould cavity with dimensions of $300 \mathrm{~mm} \times$ $400 \mathrm{~mm} \times 20 \mathrm{~mm}$ was designed. According to the calculation formula of carbon equivalent of HCCI as shown in equation 1, the carbon equivalent was between 4.299 to 4.665 . The eutectic point of HCCI was 4.26, so the HCCI was hypereutectic ${ }^{[6]}$.

$$
\mathrm{CE}=\mathrm{C} \%+0.05(\mathrm{Cr} \%)+0.33(\mathrm{Si} \%)
$$

Table 1: Nominal chemical compositions of LCS and HCCl (wt.\%)

\begin{tabular}{ccccccc} 
Contents & C & Si & Mn & Cr & S & P \\
\hline LCS & $0.33-0.45$ & $0.8-1.0$ & - & - & $\leqslant 0.03$ & $\leqslant 0.03$ \\
$\mathrm{HCCl}$ & $3.0-3.2$ & $0.3-0.5$ & $0.6-0.8$ & $24-26$ & $\leqslant 0.10$ & $\leqslant 0.10 \leqslant$
\end{tabular}

Based on the double gating system of compound casting technology, the sand mould was designed as shown in Fig. 1a. When the upper surface of the LCS from pouring gate I presented the semisolid phase, the HCCI from pouring gate II was poured into the mould cavity. The temperature field of the firstly poured LCS may be adjusted through the external chill located at the bottom of the mould cavity, for which the location and quantities of the chilling materials were specially designed. The thickness of the external chill with $300 \mathrm{~mm} \times 400 \mathrm{~mm} \times 20$ $\mathrm{mm}$ in dimension at the bottom of the cavity central area was about $0.5 T$ (where $T$ is the diameter of the hot spot of the LCS, equals to the thickness of the LCS $)^{[15]}$. When the poured molten LCS was below $10 \mathrm{~mm}$ in height in the cavity, the defects of iron beans and cold insulation easily appear at the bottom of LCS adjacent to the external chill ${ }^{[10]}$. So the LCS height should not be less than $10 \mathrm{~mm}$. In this experiment, the LCS has a depth of $10 \mathrm{~mm}$, and the poured temperature of the LCS is controlled between $1,793-1,823 \mathrm{~K}^{[5]}$. When the upper surface of the LCS maintained a semisolid state based on the detection of the Sixteen Channel Tour-inspector, liquid HCCI at 1,773-1,793 K was subsequently poured into the mould cavity after $5-15 \mathrm{~s}^{[5]}$.

To confirm the rationality of the experimental program, CAE/InteCAST10.0 solidification simulation integrated software was used to analyze the temperature distribution of the LCS. According to the simulation results in Fig. 1b, the LCS temperature field in the vertical section showed a large temperature gradient. During the LCS solidification process, the external chill can significantly increase the temperature gradient at the LCS solid-liquid interface, thus the LCS tends to form a layered solidification mode from the bottom up.

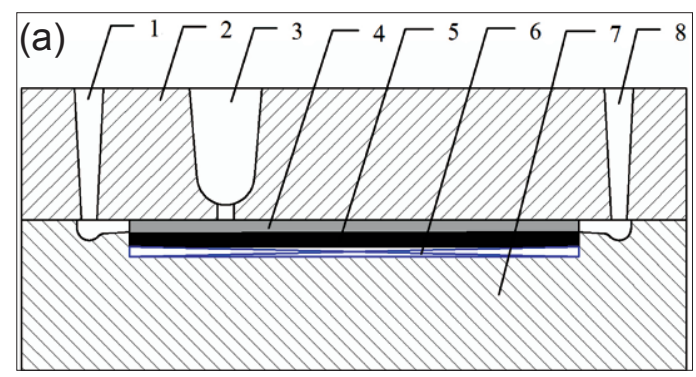

1- Pouring gate I; 2- Cope box; 3 -Riser; 4- HCCl; 5- LCS

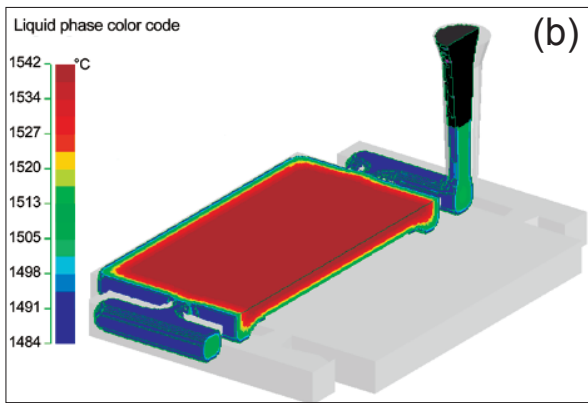

6- External chill; 7- Drag box; 8- Pouring gate II

Fig. 1: Liquid-liquid casting technology (a) and temperature color code of liquid phase (b)

The prepared liquid-liquid bimetal composite plate is shown in Fig. 2a. The plate was then cut into the samples with $10 \mathrm{~mm}$ $\times 10 \mathrm{~mm} \times 20 \mathrm{~mm}$ in dimension using a wire cutting machine according to Fig. 2b. The microstructure was observed through optical microscopy (OLYMPUS-GX71, Olympus, Japan) and scanning electron microscopy (SEM) (JSM-6360LV, JEOL, Japan). The Vickers hardness of the compound layer and the transition layer was measured by means of the microhardness tester (MC010-HVS-1000Z, China). The chemical component was studied using energy dispersive spectrdmeter (EDS) analysis (FALCON60) installed on the SEM, and the crystal structure and phase were investigated using X-ray diffraction
(XRD). The microstructure was observed using a transmission electron microscope (TEM) (Tecnai G2 F30, USA).

\section{Results and discussion}

\subsection{Microstructure of composite layer}

The scanned interface and its vicinity between the HCCI and the LCS are shown in Fig. 3. The sequence of the microstructure from the LCS to the HCCI was as follows in Fig. 3a: LCS $\rightarrow$ LCS transition layer $\rightarrow$ composite layer $\rightarrow$ HCCI transition layer $\rightarrow$ HCCI. The LCS microstructure mainly contained ferrite 

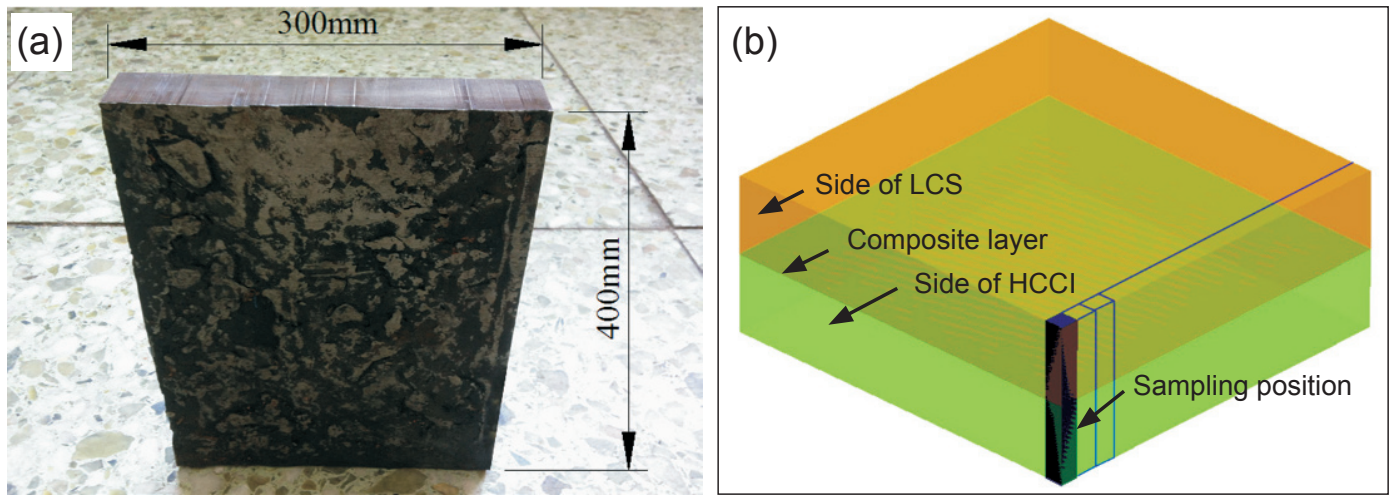

Fig. 2: Liquid-liquid casting bimetal composite plate and samples: (a) composite plate; (b) cutting method of samples

and pearlite as shown in Fig. 3b. The HCCI microstructure was mainly composed of primary eutectic carbide and eutectic ledeburite in Fig. 3c. The primary eutectic carbides were mainly $\mathrm{M}_{7} \mathrm{C}_{3}\left((\mathrm{Fe}, \mathrm{C})_{7} \mathrm{C}_{3}\right)$ which are hexagonal prismatic or hexagonal pyramid-shaped crystals ${ }^{[5]}$. The visible hexagonal crystal section has the hole which was filled with the austenite or austenitic transformation product. After the primary phase precipitation, with the temperature decreases the eutectic transformation occurred in liquid alloy phase, thus the transformation products were the $\gamma$-Fe and $\mathrm{M}_{7} \mathrm{C}_{3}$, and $\mathrm{M}_{7} \mathrm{C}_{3}$ carbide showed the strip or bar shape.

The evolution of the composite layer and the two transition layers was attributed to the remelted LCS changing the local composition between the HCCI and the LCS in Fig. 4. When liquid HCCI contacted the liquid LCS surface, the original crystal nucleus or dendrite inside the original liquid surface was remelted under the external heat. With the increasing of remelted region depth towards the LCS, the heat provided by the foreign liquid HCCI was not enough to remelt the LCS, so the heterogeneous nucleation began to occur on the LCS surface. The austenite below the composite layer first began to grow as planar crystal towards the liquid HCCI interior, and then the composite layer about $80 \mu \mathrm{m}$ in thickness formed in Fig. 4a. The diluted hypereutectic HCCI composition can be hypoeutectic, eutectic and hypereutectic near the composite layer. A small amount of eutectic transformation microstructure was mainly $\gamma-\mathrm{Fe}+\mathrm{M}_{7} \mathrm{C}_{3}$ among the dendritic austenite along the longitudinal growth in Fig. $4 b^{[10]}$. According to the previous analysis, the remelted LCS under the influence of the overheated HCCI was favorable to a small amount of $\mathrm{Cr}$ and $\mathrm{C}$ diffused from the HCCI to the LCS, promoting the formation of the LCS transition layer composed of the pearlite structure. Meanwhile chromium raised the eutectoid transformation temperature, so the increased
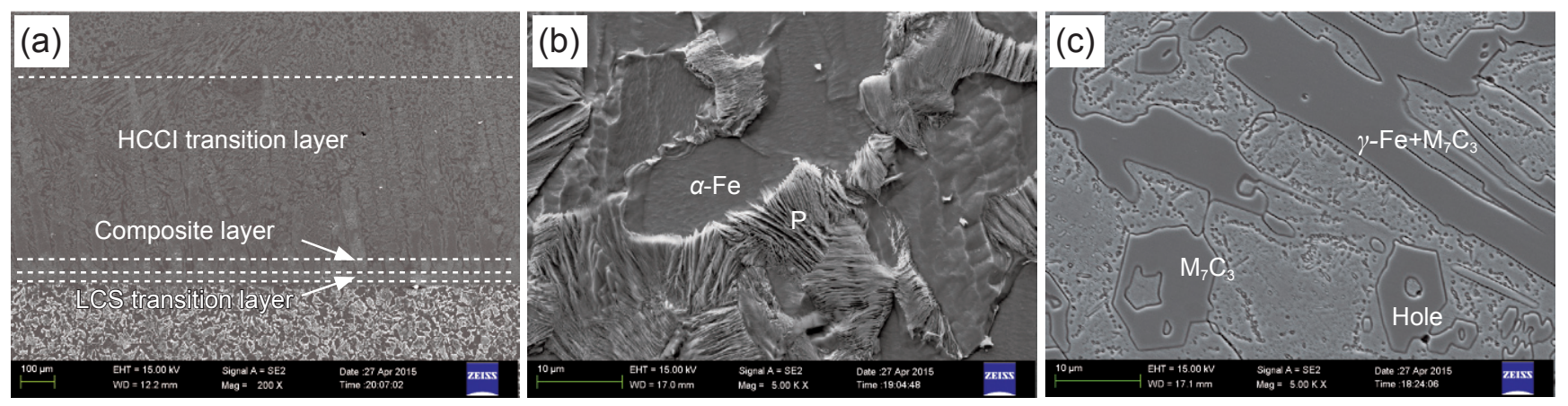

Fig. 3: Liquid-liquid bimetal composite plate microstructure: (a) composite layer and transition layer; (b) LCS; (c) $\mathrm{HCCl}$
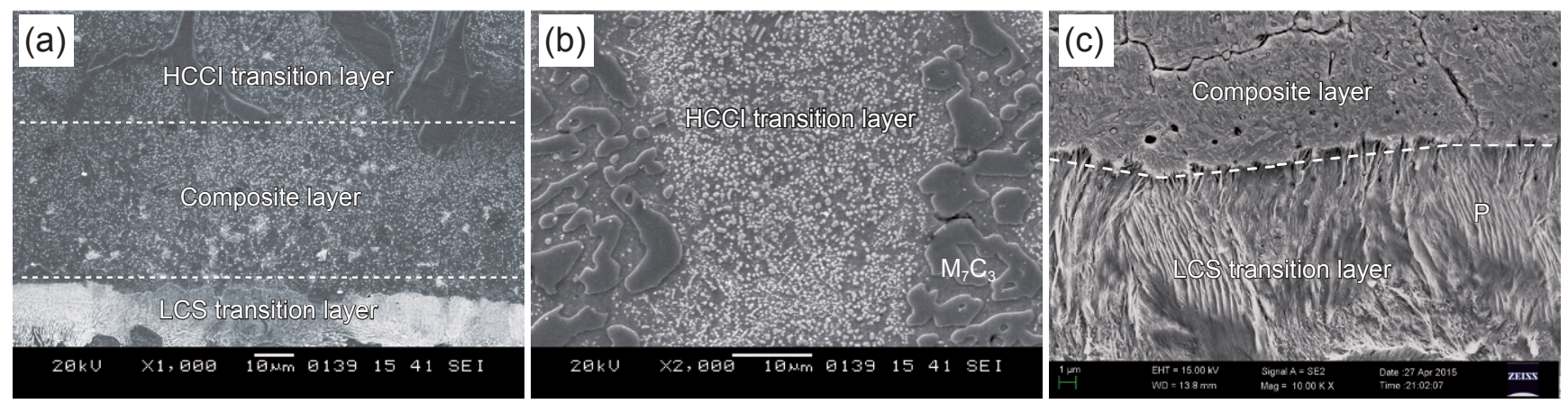

Fig. 4: SEM images of Liquid-liquid bimetal composite plate microstructure: (a) composite layer; (b) $\mathrm{HCCl}$ transition layer; (c) LCS transition layer 
supercooling degree can stimulate the formation of the very fine pearlite with small interlamellar spacing as shown in Fig. 4c.

In order to further determine the content and phase of the matrix and the granular phase among the composite layer and two transition layers shown in Fig. 4, EDS analysis was carried out as shown in Fig. 5a, and the positions of A and B were taken in the granular structure. As can be seen from the peak of the spectrum analysis, the elements at point $\mathrm{A}$ were $\mathrm{Cr}$ and $\mathrm{C}$, and the elements at point $\mathrm{B}$ were mainly $\mathrm{Fe}, \mathrm{C}$ and $\mathrm{Cr}$. The $\mathrm{C}$ and $\mathrm{Cr}$ contents of the granular phase were apparently higher than those of others, but the austenite based on Fe contained a large amount of $\mathrm{C}, \mathrm{Cr}$, and minor $\mathrm{Mn}$ and $\mathrm{Si}$, as shown in Fig. 5b (point B). According to the XRD diffraction analysis as shown in Fig. 5c, the main phases were as follows: $\mathrm{M}_{7} \mathrm{C}_{3}\left((\mathrm{Fe}, \mathrm{Cr})_{7} \mathrm{C}_{3}\right), \alpha$-Fe, $\gamma$-Fe, ( $\mathrm{Fe}, \mathrm{Cr}$ ), $\mathrm{FeCr}, \mathrm{Fe}_{3} \mathrm{C}$ and $\mathrm{Cr}_{7} \mathrm{C}_{3}$. Results of TEM tests of the areas within the two circles in Fig. $5 \mathrm{~d}$ indicated that the phase was $\mathrm{Cr}_{7} \mathrm{C}_{3}$, and the matrix metal was $\gamma$-Fe.
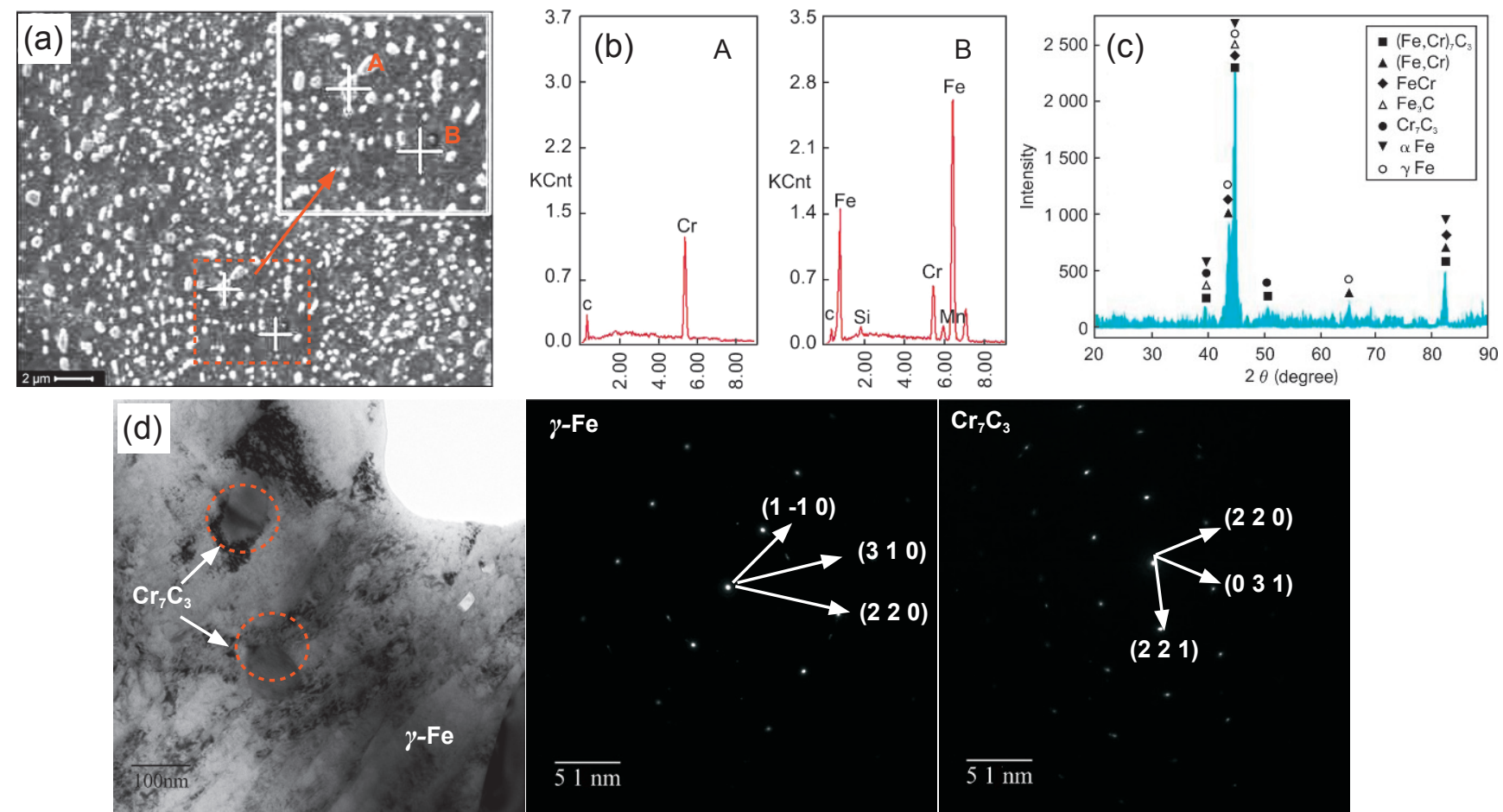

Fig. 5: Content and microstructure analysis using EDS, XRD and TEM: (a) Position of $A$ and $B$ EDS; (b) EDS values of $A$ and B; (c) XRD analysis of composite layer and $\mathrm{HCCl}$ transition layer; (d) TEM analysis of composite layer

The sequence of the phase evolution from the LCS to the HCCI was as follows: $\operatorname{LCS}(\alpha-\mathrm{Fe}+\mathrm{P}) \rightarrow$ LCS transition layer $(\mathrm{P}) \rightarrow$ composite layer $\left(\gamma-\mathrm{Fe}+\mathrm{Cr}_{7} \mathrm{C}_{3}\right) \rightarrow$ HCCI transition layer (primary dendritic austenite $(\gamma-\mathrm{Fe})+$ ledeburite $(\gamma-\mathrm{Fe}+$ $\left.\left.\mathrm{M}_{7} \mathrm{C}_{3}\right)\right) \rightarrow$ HCCI (primary eutectic carbides $\left(\mathrm{M}_{7} \mathrm{C}_{3}\right)+$ eutectic transformation ledeburite $\left.\left(\gamma-\mathrm{Fe}+\mathrm{M}_{7} \mathrm{C}_{3}\right)\right)$. The Vickers hardness was tested using the microindentation method.

The results are shown in Fig. 6. The microhardness of the composite layer and transition layer showed regular changes. The Vickers hardness of the pearlite transition layer ranged from 314 to 333, and the Vickers hardness range of the HCCI transition layer was from 915 to 962 . The Vickers hardness range of the composite layer was from 360 to 855 between the LCS transition layer and the HCCI transition layer.

\subsection{Formation mechanism of composite layer}

Due to the significant increase of chromium content towards the HCCI, a relatively uniform composite layer formed through the fused surface film between HCCI and LCS, therefore the microstructure of the composite layer was mainly $\gamma$-Fe because chromium can stabilize the austenite. Because of the faster solidification, a large amount of $\mathrm{C}$ and $\mathrm{Cr}$ precipitated in the form of granular $\mathrm{Cr}_{7} \mathrm{C}_{3}$ in the $\gamma$-Fe matrix.

At the beginning of the formation of the $\gamma$-Fe solid solution composite layer, the solid-liquid interface was a cutting-edge plane. With the advance of the solidification plane, the $\mathrm{C}$ and $\mathrm{Cr}$ in the hypereutectic HCCI were diluted under the interdiffusion between the HCCI and the LCS, making the HCCI composition move to the left of the eutectic point. In fact, the alloy composition was Fe-C-Cr ternary alloy at this point. Therefore, the HCCI matrix microstructure was $\gamma$-Fe based on the liquid surface projection of the Fe-C-Cr ternary phase diagram. Microstructure observation showed that $\mathrm{C}$ and $\mathrm{Cr}$ contents at the dendritic austenite forefront were significantly higher than those of the corresponding austenite inside, and the concentration of $\mathrm{C}$ and $\mathrm{Cr}$ proved their equilibrium distribution coefficients were less than 1 . When the crystal growth conditions were in line with the constitutional undercooling criterion ${ }^{[15]}$, a relatively narrow zone for constitutional undercooling formed in the liquid phase of the solidification front. The concentration of $\mathrm{C}$ between adjacent protrusions increased faster than that of the protrusion front. At the same time, the diffusion of $\mathrm{C}$ between adjacent 

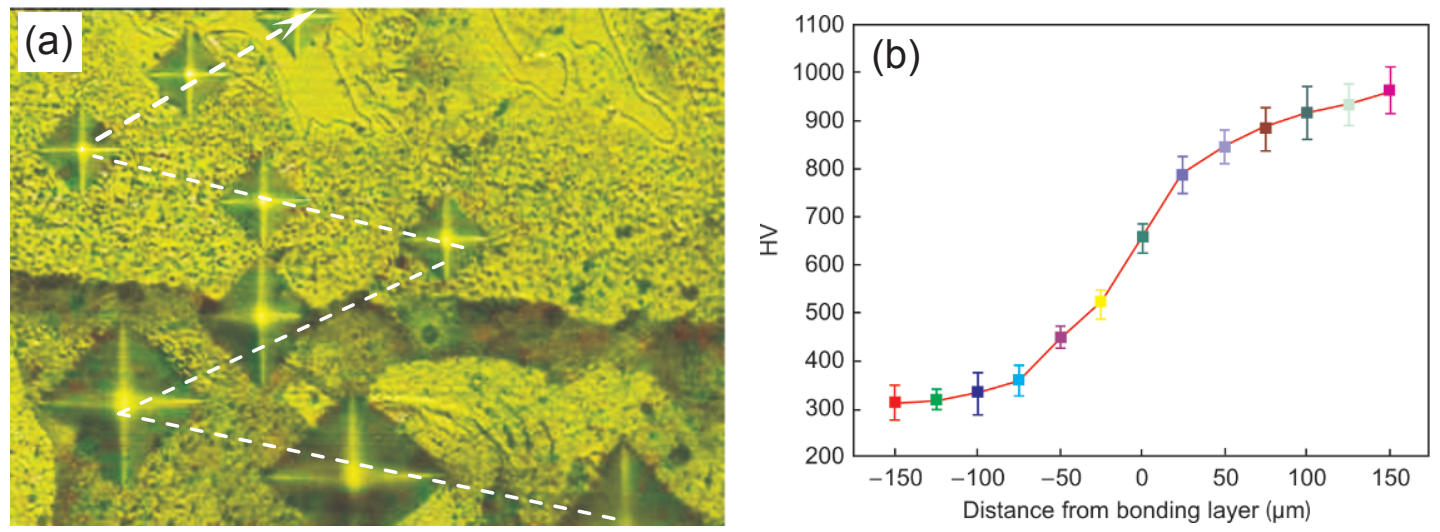

Fig. 6: Composite layer and transition layer Vickers hardness analysis: (a) Vickers hardness indentation; (b) Vickers hardness values

protrusions to the liquid HCCI was more difficult than that of the protrusions' front. Thus, the rapid growth of the protrusions resulted in the further increase of concentration of $\mathrm{C}$ between the adjacent protrusions. The higher $\mathrm{C}$ concentration decreased the HCCI alloy liquidus temperature and the degree of supercooling of the alloy liquid between the protrusions, which inhibited their lateral growth rate. The lateral component of each protrusion was very uneven compared to the growth of primary austenite. Under the $k<1$ (where $k$ is the distribution coefficients of $\mathrm{C}$ and $\mathrm{Cr}$ ), the solute content of the protrusion center part was the lowest and then increased towards the surrounding primary austenite. Furthermore, the lateral component of each protrusion was very uneven. The increased constitutional undercooling caused the instability of the solid-liquid interface, leading the initial planar growth to the cellular growth. During the cellular growth, unit cell protrusion growth was perpendicular to the isothermal surface, and its growth direction was opposite to the heat flow regardless of the crystallographic characteristics. When the liquid component of the solid-liquid interface reached the eutectic composition, and primary austenite stopped growing, the eutectic transformation of the transition layer formed the austenite and eutectic carbides. As the cooling temperature reached the eutectic transition point, the content of $\mathrm{C}$ also reached the eutectic composition among the protrusions in the liquid phase, and then $\gamma$-Fe and eutectic carbides were formed among the cellular austenite grains through eutectic transformation.

\section{Liquid-liquid composite wear steel plate}

The minimum thickness of liquid-liquid bimetal composite wear plate through the above production process can be controlled within 20-23 mm. It is shown in Fig. 7a that the substrate thickness is more than $10 \mathrm{~mm}$, and the wear layer thickness can be adjusted according to the need. Bimetal wear plates with excellent metallurgical quality can avoid the generation of micro crack source to eliminate the generation of wear layer macroscopic crack. The casting can be directly cast into a desired shape, as shown in Fig. 7b. However, the large welding wear plates need to be cut into various shapes for the different demands which will result in $25 \%$ to $40 \%$ waste of the welding wear plates. Casting wear layer with a uniform alloy composition ensures the overall wear performance of the wear layer, and then the mechanical properties can be further improved by the heat treatment. As shown in Fig. 7c, the casting wear plate can avoid the bending deformation through the inverse deformation design, but the welding wear plate is typically cold reshaping to exacerbate the initial macroscopic crack increment. The casting wear plate, compared with the welding plate of the same chemical composition, increases the service life $50 \%$ to $80 \%$ and reduces the production costs about $30 \%$.
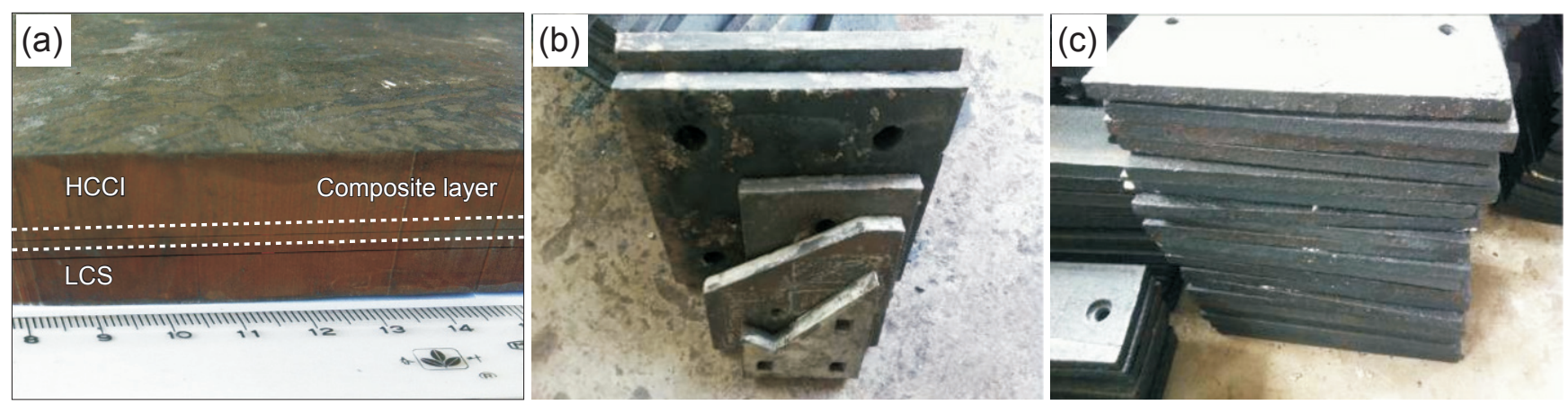

Fig. 7: Liquid-liquid bimetal LCS/HCCI composite wear plate: (a) wear plate macrostructure; (b) different shapes of wear plate; (c) deformed wear plate 


\section{Conclusions}

(1) The LCS/HCCI wear plate with a minimum thickness of about $20 \mathrm{~mm}$ was successfully prepared by the proposed bimetal liquid membrane joining method, and the sequence of the microstructure from the LCS to the HCCI was as follows: $\operatorname{LCS}(\alpha-\mathrm{Fe}+\mathrm{P})$ $\rightarrow$ LCS transition layer $(\mathrm{P}) \rightarrow$ composite layer $\left(\gamma-\mathrm{Fe}+\mathrm{Cr}_{7} \mathrm{C}_{3}\right)$ $\rightarrow$ HCCI transition layer (dendritic austenite $\left(\gamma-\mathrm{Fe}+\mathrm{Cr}_{7} \mathrm{C}_{3}\right)+$ ledeburite $\left(\gamma\right.$-Fe $\left.\left.+\mathrm{M}_{7} \mathrm{C}_{3}\right)\right) \rightarrow$ HCCI (primary eutectic carbides $\left(\mathrm{M}_{7} \mathrm{C}_{3}\right)+$ eutectic transformation ledeburite $\left.\left(\gamma-\mathrm{Fe}+\mathrm{M}_{7} \mathrm{C}_{3}\right)\right)$.

(2) The introduced chilling material can cause a higher temperature gradient in the vertical section and benefit the lamellar solidification of the LCS. When the upper surface of the LCS presents the liquid or semisolid phase, the HCCI is poured into the mould cavity, and then a good metallurgical bonded interface between the HCCI and the LCS can be achieved. The Vickers hardness of pearlite transition layer was from 314 to 333, and that of the HCCI transition layer was from 915 to 962 , that of the composite layer (between the LCS transition layer and the HCCI transition layer) was from 360 to 855 .

(3) The austenite grows as dendrites between the composite layer and the HCCI transition layer under constitutional undercooling. A large amount of $\mathrm{C}$ and $\mathrm{Cr}$, and a small amount of $\mathrm{Si}$ and Mn dissolve in the matrix. Granular $\mathrm{Cr}_{7} \mathrm{C}_{3}$ is uniformly distributed.

(4) Liquid HCCI presents non-homogeneous nucleation at the LCS surface. With the constitutional undercooling region extension at the solidification front of the liquid phase, the primary austenite growth is in accordance with the planar, celllike and dendrite. The dendrite crystals have an obvious growth direction perpendicular to the composite layer.

\section{References}

[1] Atamert S, Bhadeshia H K. Microstructure and Stability of FeCr-C Hardfacing Alloys. Materiala Science and Engineering A, 2010, 101-111.

[2] Junek L, Slovacek M. Numerical Simulation of Welding and Computation of Residual Stresses. Zvaranie (Slovacek Republic), 2000, 49(5): 44-47.
[3] Matsubara Y, Ogi K, Matsuda K. Eutectic Solidification of High Chromium Cast Iron-eutectic Structures and Their Quantitative Analysis. Transactions of the American Foundrymen's Society, 1982, 89(6): 183-196.

[4] Xiao Xiaofeng, Ye Shengping, Yin Weixin, et al. High $\mathrm{Cr}$ white cast iron/carbon steel bimetal liner by lost foam casting with liquid-liquid composite process. China Foundry, 2012, 2: 136142.

[5] Rong Shoufan, Liu Chuang, Guo Jiwei, et al. Influence of casting technique on the mechanical properties of bimetal composites. Journal of Iron and Steel Research International, 2011, 31: 562-565.

[6] Rong Shoufan, Zhou Haitao, Zhu Yongchang, et al. Study on liquid-liquid bimetal composite casting hammers. China Foundry, 2014, 11: 412-417.

[7] Liang He, Xie Zhiyong, Wu Chunking, et al. Research on continuous core-filling casting forming process of copper-clad aluminum bimetal composite material. Acta. Metall. Sin. (Engl. Lett.), 2010, 23: 206-214.

[8] Xiong Guangrao, Zheng Meizhu, Zhao Longzhi. Research state on technology of metal matrix composites prepared by casting process. Casting Technology, 2006, 4: 563-565. (In Chinese)

[9] Prasad B K, Modi O P, Patwardhan A K. Effects of some material and experimental variables on the slurry wear characteristics of zinc-aluminum alloys. J. Mater. Eng. Perform, 2001, 10: 75-80.

[10] Rong Shoufan, Zhu Yongchang, Shi Chunyan, et al. Study on lining board with bimetal liquid composite casting. Advanced Materials Research, 2011, 317: 158-161

[11] An Jiangying, Qi Jiyu. Microstructure and properties of bimetal composite on high chromium cast iron and carbon steel. Water Conservancy and Electric Machine, 1992, 8: 49-53. (In Chinese)

[12] Joseph C. Benedyk. Novelis Fusion Process-Breakthough in the simultaneous DC casting of multiple aluminum alloy layers for rolling ingot. Light Metal Age, 2006, 8: 48-50.

[13] Takeuchi E, Zeze M, Tanaka H, et, al. Mizoguchi. Novel continuous casting process for clad steel slabs with level DC magnetic field. Iron making and Steel making, 1997, 24(7): 257-261.

[14] Asta M, Beckermann C, Karma A. Solidification microstructures and solid-state parallels: Recent developments, future direction. Acta Materialia, 2009, 57: 941-971.

[15] Li Qingchun. Basis of Cast Forming Theory. Beijing: Mechanical Industry Press, 1982, Chapter 4: 127. (In Chinese)

\footnotetext{
This work was financially supported by the National Natural Science Foundation of China Project under grant No. 51371090, the Science and Technology Support Program of 12th Five-Year Plan under grant No. 2011BAD20B03010401, the Educational Department Surface Project of Heilongjiang Province under grant No. 12521519, the Cultivation Plan of the New Century Excellent Talents of Heilongjiang Province under grant No. 1155-NCET-017, the College Student Science and Technology Innovation of Heilongjiang Province under grant No. 201410222037, the College Student Science and Technology Innovation of Jiamusi University under grant No. xsld2014-002, and Graduate Student Science and Technology Innovation of Jiamusi University LZR2014_007
} 